\title{
Bringing Consistency in the Websites of Higher Educational Institutes (HEIs) of Pakistan
}

\author{
Wajid Arshad Abbasi ${ }^{1 *}$, Muhammad Aihab Khan ${ }^{2}$, Fazal Wahab ${ }^{3}$ \\ 1, 2,3 (Department of Computing and Technology, Iqra University, Islamabad, Pakistan) \\ ${ }^{I}$ (Software Research \& Development (SR\&D) Section, University of Azad Jammu \& Kashmir, Muzaffarabad, \\ Pakistan) \\ ${ }_{3}^{3}$ (Department of Applied Sciences and Graduate Studies, Bahria University, Islamabad, Pakistan)
}

\begin{abstract}
The aim of this research is to bring consistency in the Higher Educational Institute's (HEI's) websites of Pakistan through a framework for designing HEI's websites. HEI's websites have a lot of contents to be placed at the right corner. These intend to offer information for prospective students, their parents, existing students, alumni, faculty members and staff. Our results show that majority of HEI's websites in Pakistan are not designed by following specific framework. These websites show inconsistent information which makes it difficult to search the required information. Major problem of inconsistency was observed through comparative analysis and survey. The basic methodology for this research work was interviews, questionnaire and usability evaluation. Experimental results show that consistency in websites promotes usability which will make the websites easy to use and easy to learn. We concluded that standards, conventions, templates and patterns should be designed and applied during the design, development and maintenance of HEI's websites.
\end{abstract}

Keywords: Consistency, Higher education, Human computer interaction, Usability engineering, Websites in Pakistan.

\section{INTRODUCTION}

The main aim of HEI's websites in Pakistan is to show information regarding institute and to provide services to students, parents, faculty members and staff. The students and faculty members explore these websites to get necessary information. The major challenges are to access this information effectively and efficiently by all stakeholders. Students start accessing these websites for seeking admission and continue till their graduation as well as after graduation. If website is not easy to use and learn, then visitors may immediately switch to other website [1]. Before using any system, user always develop some understanding about the behavior of the system which is called Mental Model. The success of this mental model depends upon many factors i.e. consistency etc, which relates performing actions based on previous experiences [2]. Consistency is considered to be one of the most important usability characteristics which will make the product easy to use and learn. In a website, consistency means that the same sequence of actions results in the same output [3].

Conventional marketing wisdom would say that all materials within a brand should have a similar look and feel to maintain the brand. Under this wisdom, the web should not be treated differently than maintaining a similar look and feel throughout the websites. The scheme of consistency on websites is quite straightforward when users navigate from page to page, related contents or services should be accessible in comparable fashion and on similar location. A consistent user interface always presents related information similarly everywhere on the site. Moreover, consistency also improves productivity as user can always predict system behavior [4].

Usually, the consistency in the websites is measured in the form of features like color (background and font), font-size, typography and standard navigation bar [5]. Therefore, a website is considered to be consistent if the similar standards for the maximum features have been used in the entire website.

This research aims to examine the consistency with respect to perceptions and expectations of both the stakeholders of Higher Education Commission (HEC), and the HEI's of Pakistan, in relation to functionality/services provided in their websites. The ultimate goal of this research is to propose a framework for the development of HEI's website in Pakistan.

The rest of the paper is structured as follows: Related work has been discussed in section II, methodology and data analysis is presented in section III, findings are elaborated in section IV, section V describes complete framework of websites design, section VI presents discussion, the paper is concluded in section VII along with future work and the acknowledgments are presented in section VIII.

\section{RELATED WORK}

Literature on a website's design and development shows that the quality of educational websites mainly depends on its consistent interface [6-9]. Better the quality of the interface of the education related software better will be the learning progress of the students [10,11]. Crowther et al. [12] affirmed that improper 
interface design has more serious effects on educational systems than business related. It not only effect student's impression but also has serious impacts on the whole progress and everyday learning. In crux, to improve the quality of any e-learning system there is a need to improve its interface [7, 10, 13, 14].

Significant work has been done to propose various principles and standards to build easy to navigate websites $[15,16]$. One of these principles is to have consistent navigational system, which is of course most important consistency design feature [17, 18]. For example, users cannot perform efficiently if navigation bar is on right hand side against recommendations of left hand side [19, 20]. Interface consistency always relates to interface design. Increasing consistency results in decrease error rate in web based tasks [21, 22]. Improved consistency helps students to get familiar with the system immediately [23]. Consistent software systems always behave in expected manner [8].

Usability evaluation and recognition of the role of user are important in the construction of websites [24]. Powell, [25] described websites composed of two structures; first is logical, which related to the way the information linked and how the user navigate and the second is physical, which relates to the localization of information. The logical structure depends on layout of the page, navigation, links, search, structure and interactivity [25]. The best practice to assess the usability of website is to have usability analysis in an iterative design process [26].

Developing online services for the students which can be used conveniently and comfortably are the need of the time. Studies tell us that students always seeks for a well-organized, easy to use technology that allows them to efficiently complete their tasks, locate information, and communicate electronically [27]. A university is considered to be technological advanced which promotes education through virtual learning system [27]. Most of studies show the significance of interface consistency in web based applications; however they are either case studies or academic in essence. Good educational website can significantly contribute toward improvement of interaction between students and faculty members.

\section{METHODOLOGY AND DATA ANALYSIS}

The methodology adopted for this research was interviews, questionnaire and usability evaluation. The interviews were conducted with the stakeholders of HEC and some public sector universities of Pakistan. In interview, more focus was on the faculty members and students who are considered to be the major stakeholders. A questionnaire (88 questions) was designed and distributed amongst the major stakeholders of HEI's websites. The questionnaire was based on the functionality/services provided by the university's website. Most of the questions were asked about function and service which are required by the user and also for its usability attribute.

The data collected through interviews and questionnaire was analyzed statistically and manually to generate results which are presented in following section.

\section{A. Interview of Stakeholders in HEC and HEIs}

\section{FINDINGS}

To evaluate the expectations and needs of HEC, Pakistan for HEI's websites, interviews were conducted with

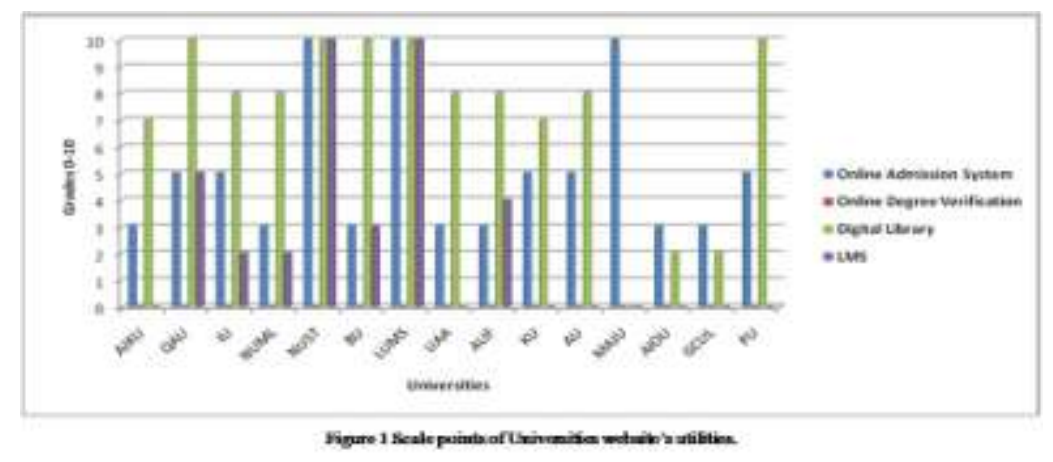

the stakeholders of HEC and HEIs. In each interview, different aspects related to service provision were discussed and major utilities and functionalities were highlighted. Utilities and functionalities discussed in previous section were identified in almost 15 different universitie's websites of Pakistan. Scale from 0 to 10 was given to each utility discussed in interview while analyzing websites of respected universities. The scales were compiled and the results are shown in Figure 1.

The other information like complete name of University for each abbreviation and their URLs are given in Appendix 1. 


\section{B. Measuring consistency through questionnaire}

A questionnaire was developed to evaluate consistency in different universities websites. The Questions were organized in different categories of related features. The first portion of questionnaire was divided into two groups; common features and highly recommended features as shown in Appendix 2. This

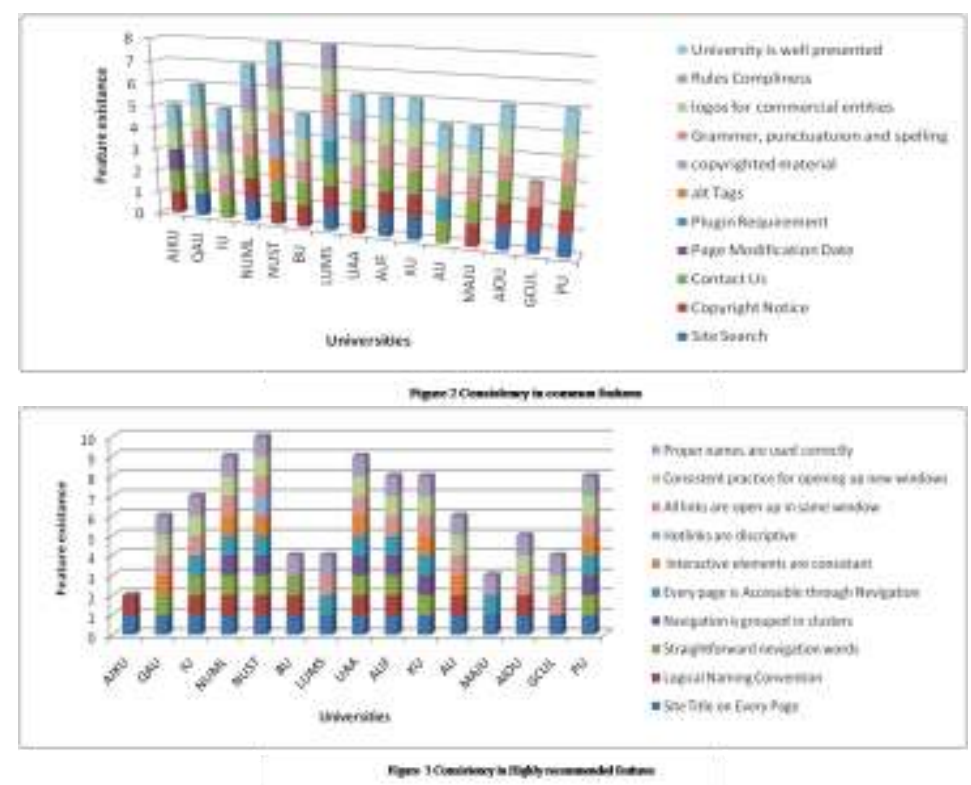

questionnaire was distributed to several students and faculty members of various universities and age groups. After results computation and data analysis, the results are shown in Figure 2 and 3.

Five different universities were compared with respect to certain features by each student (S1, S2: average scores) and faculty member (T1: average scores). Score to each web site was given using a number from -10 to +10 , including 0 . 0 means that the criterion is not available at all to score. Scores from +1 to +10 relate to the how well the criterion is being represented, where +1 indicates that the criterion is represented, and +10 indicate that the criteria is extremely well represented. Scores from -10 to -1 relate to how distracting or irritating the criterion is where -10 indicate a major distraction/irritant and -1 a minor distraction/irritant. The

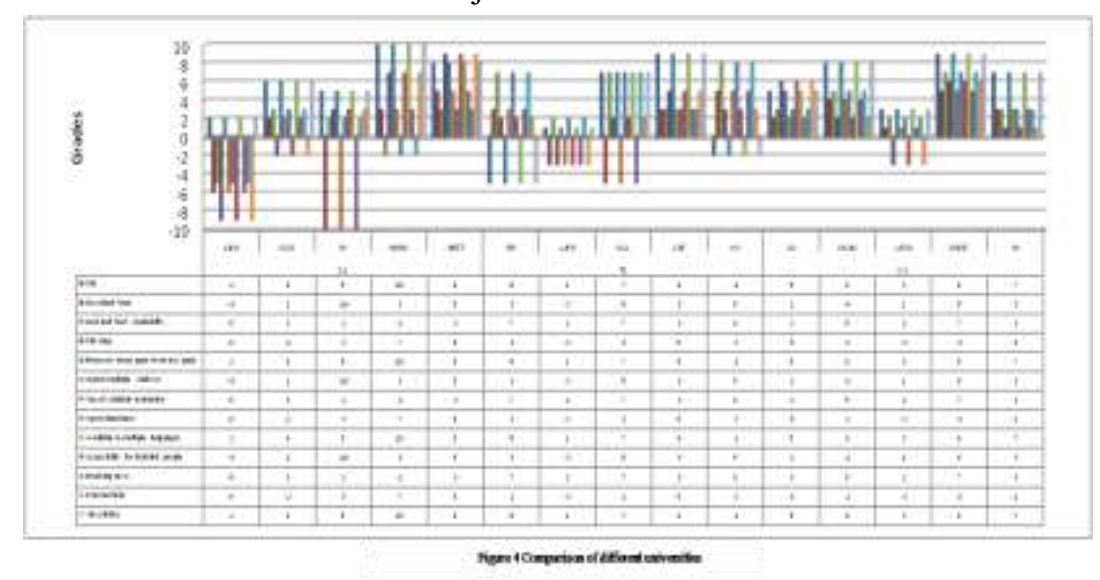

results are shown in Figure 4. The accumulative scores given by students and faculty members to different features are shown in figure 5.

After analyzing the data shown in figures 1 to 5 , it can easily be deduced that there is an extreme lack of consistency in HEI's websites of Pakistan. The sites are not properly designed and even in some websites the basic functionalities are not provided. Each website should justify that why one should access it on web through proper services. Some university's websites are nothing more than just static web pages displaying university's introduction. 


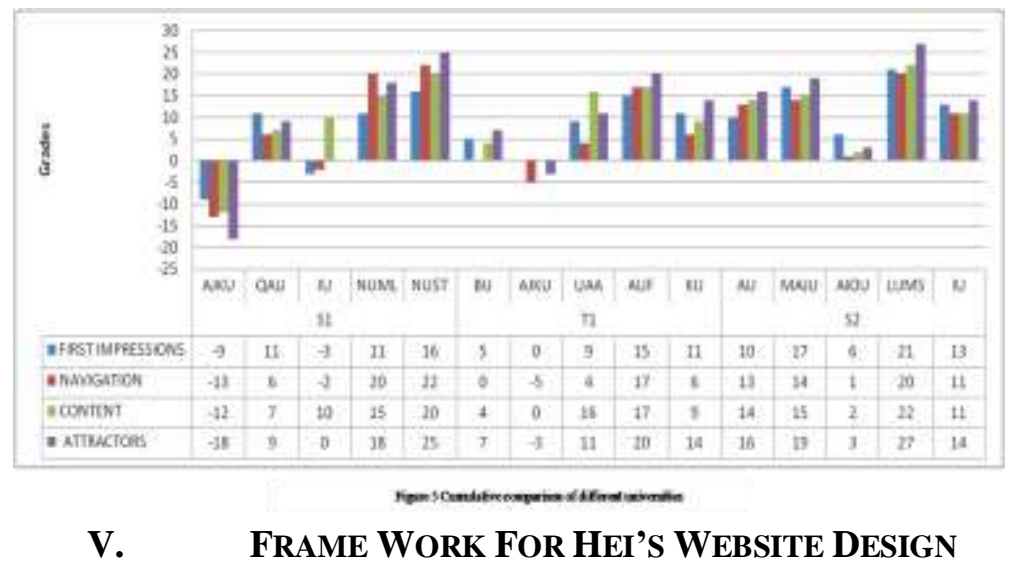

Based on the strong feedback of major stakeholders involved in universities website design, a framework has been proposed as guidelines to develop consistent HEI's website in Pakistan. The framework is shown in Figure 6.

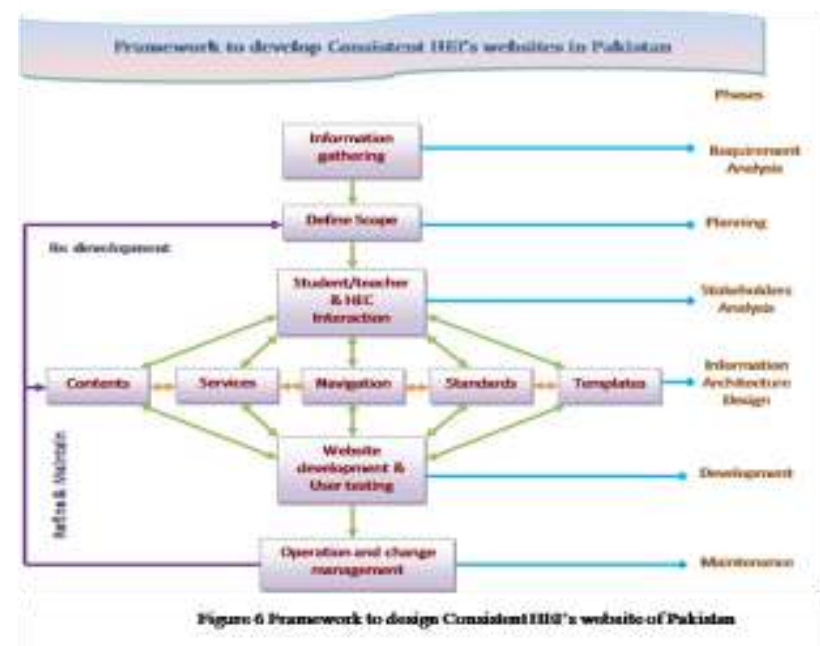

This framework emphasizes on stakeholder's analysis and Information Architecture Design (IAD) using templates and standards. The main phases of framework are elaborated as follows:

\section{A. Requirement Analysis}

Requirement analysis phase involves gathering all the required information necessary to plan and develop the website. This phase is extremely necessary as it helps to find what to build and also multi rounds to customer can be avoided. Essentially, this phase enables one to tell the stakeholder what you require and what your website needs to achieve.

\section{B. Planning}

This phase aims to define the scope of work by defining goals, budget constraints, completion time, targeted audience, design requirements, technology and infrastructure. Consultancy with experienced designers and project managers may also be required during this phase.

\section{Stakeholders Analysis}

Stakeholder analysis involves what are the stakeholders, their characteristics, nature and level of interest, and how they will be affected by the project. In the development of HEI's website, the main stakeholders are faculty members, students and HEC. To design a quality website, needs and requirements of all the stakeholders must be considered. It helps better user bye in and to understand what is important to everyone.

\section{Information Architecture Design}

Steps involved in defining effective site organization and navigation are called IAD. Content Writing and visual design creation \& modifications are performed during this phase. Information architecture helps to draw site map. This is an important phase for designing consistent HEI's websites as all the specified standards, templates and checklists are considered during this phase. Standards like W3C and templates help to improve identity, flexibility, usability and consistency in the HEI's websites. 
E. Development

This phase involves building the website according to IAD. During development continuous feedback from the stakeholders plays important role to fulfill the requirements and usability of the website. This feedback can be achieved through user testing during the development of website.

F. Maintenance

Website maintenance involves changing contents and increasing return traffic to website. It plays important role in areas like publishing, quality assurance, feedback monitoring, performance monitoring and infrastructure monitoring. Change management in maintenance coordinates all the technical and other changes. Maintenance may involve just refinement where only IAD needs to be redesign but when maintenance involves redevelopment then scope must be redefined.

\section{DISCUSSION}

A website should be created after complete understanding of needs and expectations of its prospective users. Contents, graphical design, organization and navigation should be designed in such a way that allows visitors to access information and complete critical tasks with ease [28]. These aspects have even greater importance for HEI's websites where users come from variety of different backgrounds. Normally expectations of visitor to a HEI's website seem to be same as all the visitors belong to faculty member or students group. Therefore HEI's websites should be consistent in terms of services and functionality. But in case of websites of HEI's of Pakistan, they are designed very poorly without considering consistency and usability aspects.

Major reason of inconsistencies in the HEI's website's design is lack of proper framework to design the websites. A framework has been designed shown in figure 6, to fill this gap. Major emphasis in framework is on IAD which enables intuitive use of website [29]. For proper IAD there should be proper standards, guidelines and templates which are currently unavailable. Initiative must be taken by HEC to design templates and standards for consistent HEI' website design.

\section{CONCLUSION AND FUTURE WORK}

In a random survey of websites of HEI's of Pakistan, it has been observed that websites are not consistent in terms of functionality/services. Most of the websites does not justify their usability. The basic reason for inconsistency is lack of specific framework to design consistent websites according to HEC guidelines. A frame work has been recommended while keeping in view the interest and expectation of different stakeholders of universities. The proposed framework can be used as a guideline for designing HEI's websites. Comparative and competitive analysis of the given framework with current website development strategies in Pakistan will be done in future. The results of this study could also be expanded to other corporate websites at national and international level.

\section{ACKNOWLEDGEMENTS}

We wish to thank all of our friends and colleagues who contributed to this research work.

\section{REFERENCES}

[1] J. Nielsen, Designing Web Usability: The Practice of Simplicity (New Riders Publishing, 2000).

[2] A. Dix, J. Finlay, G. Abowd, and R. Beale, Human-Computer-Interaction (Prentice Hall International (UK) Limited, 1992).

[3] J. Nielsen, Usability Engineering (Academic Press, 1993).

[4] J.Nielsen, Coordinating User Interfaces for Consistency, the Morgan Kaufmann Series in Interactive Technologies (Morgan Kaufmann, San Francisco, CA, 2001).

[5] D.Brannon, and A. Sellati, Design Consistency, Website Development and Administration, (2000), at http://slis-two.lis.fsu.edu/ consist/ introduction.html.

[6] J. Buzhardt, M. Abbott, C. Greenwood, and Y. Tapia, Usability testing of the ClassWide peer tutoring-learning management system, Journal of Special Education Technology, 20 (1), (2005), 19-29.

[7] V. Cantoni, M. Cellario, and M. Porta, Perspectives and challenges in e-learning: towards natural interaction paradigms, Journal of Visual Languages and Computing, 15, (2004), 333-45.

[8] L.F. Chu, and B.K Chan, Evolution of Web site design: implications for medical education on the Internet, Computer in Biology and Medicine, 28, (1998), 460-72.

[9] J.E. Hinostroza, and H. Mellar, Pedagogy embedded in educational software design: report of a case study, Computers \& Education, 37, (2001), 27-40.

[10] B. Gauss, and L. Urbas, Individual differences in navigation between sharable content objects - and evaluation study of a learning module design, British Journal of Educational Technology, 34 (4), (2003), 499-509.

[11] D.H. Jonassen, and S. Wang, Acquiring factual knowledge from semantically structured hypertext, Journal of Computer-Based Instruction, 20 (1), (1993), 1-8.

[12] M.S. Crowther, C.C. Keller, and G.L. Waddoups, Improving the quality and effective of computer-mediated instruction through usability evaluations, British Journal of Educational Technology, 35 (3), (2004), 289-303.

[13] C. Chou, Interactivity and interactive functions in Web-based learning systems: a technical framework for designers, British Journal of Educational Technology, 34(3), (2003), 265-79.

[14] K. Ellis, and K. Blashki, Toddler techies: a study of young children's interaction with computers, Information Technology in Childhood Education Annual, (2004), 77-96.

[15] D.K. Farkas, and J.B. Farkas, Guidelines for designing web navigation, Technical Communication, 47(3), (2000), 341-358

[16] J. Fleming, Web navigation: designing the user experience (O'Reilly, Sebastopol, 1998). 
[17] B. Shneiderman, Designing the user interface, Strategies for effective human-computer interaction (Addison-Wesley Publishing, 1998).

[18] B. Tognazzini, First principles of interaction design, at http://www.asktog.com/basics/firstPrinciples.html

[19] J. Kalbach, and T., Bosenick, Web page layout: a comparison between left- and right-justified site navigation menus, Journal of Digital Information, (2003), 4(1).

[20] U.S. Department of Health and Human Services, Research-based web design and usability guidelines, (2006), at http://www.usability.gov/pdfs/guidelines.html\#1.

[21] A.A. Ozok, and G. Salvendy, Twenty guidelines for the designing of Web-based interfaces with consistent language, Computers in Human Behaviour20, (2004), 149-61.

[22] A.A. Ozok, and G.,Salvendy, The effect of language inconsistency on performance and satisfaction in using the Web: results from three experiments, Behavior and Information Technology, 22(3), (2003), 155-63.

[23] D. Gerrett, S. Threadgold, and A. Lloyd, Quality assurance for computer-based teaching and learning packages, Quality Assurance, 6 (1), (1998), 52-7.

[24] A, L. Jose, and H. C. Jose, A usability evaluation of educational websites, EADTU Conference, (2008), at http://www.eadtu.nl/conference-2008/.

[25] P. Powell, Web Design: The Complete Reference ( New York: McGraw-Hill. 2000).

[26] S. Atilano, S. M. Rui, and C. Eurico, The role of usability in the competitiveness of higher education institutions, IADIS International Conference Applied Computing, (2006), 307-314.

[27] C. Sandra, A. Hope, H. Christine, and W. Robert, Web Site Usability in Higher Education, ISECON, 22, (2005),1-11.

[28] T. Brinck, et al., Usability for the Web: Designing Web Sites that Work( London: Academic Press, 2002).

[29] L. Rosenfeld, and M. Peter Information Architecture for the World Wide Web (2nd Edition, Sebastopol, CA: O’Reilly, 2002).

Appendix 1: Universities of Pakistan and their URLs

\begin{tabular}{|c|l|l|l|}
\hline S\# & Abbreviation & University Name & URL \\
\hline 1 & AJKU & Azad Jammu \& Kashmir University & www.ajku.edu.pk \\
\hline 2 & QAU & Qaid-i-Azam University & www.qau.edu.pk \\
\hline 3 & IU & Iqra University & www.iqra.edu.pk \\
\hline 4 & NUML & National University of Modern Languages & www.numl.edu.pk \\
\hline 5 & NUST & National University of Science \& Technology & www.nust.edu.pk \\
\hline 6 & BU & Bahria University & www.bahria.edu.pk \\
\hline 7 & LUMS & Lahore University of Management Sciences & www.lums.edu.pk \\
\hline 8 & UAAR & University of Arid Agriculture Rawalpindi & www.uaar.edu.pk \\
\hline 9 & AUF & Agriculture university Fasialabad & www.uaf.edu.pk \\
\hline 10 & KU & Karachi University & www.uok.edu.pk \\
\hline 11 & AU & Air University & www.au.edu.pk \\
\hline 12 & MAJU & Muhamad Ali Jinnah University & www.jinnah.edu.pk \\
\hline 13 & AIOU & AlamaIqbal Open University & www.aiou.edu.pk \\
\hline 14 & GCUL & Government College University Lahore & www.gcu.edu.pk \\
\hline 15 & PU & Punjab University & www.pu.edu.pk \\
\hline
\end{tabular}

Appendix 2: Questionnaire to evaluate Website consistency

This questionnaire is to evaluate the website consistency of HEIs of Pakistan

1- Name

3- University

\section{2- Role}

4- URL

\section{Faculty Member/Student}

Questionnaire (Please answer question impartially after visualizing/using the website)

\section{Part I}

Common features ( $\checkmark$ the available feature)

$\square$ Is there a link to either the University's search or a site-specific search from your site's home page?

$\square$ The University's copyright notice, including the current year, exists on your site's home page.

$\square$ Contacts for site owners are provided somewhere within your site.

$\square$ A page modification date exists on your site's home page.

$\square$ Your site provides critical information in a format that does not require a plug-in (third-party software) for viewing.

$\square<$ alt $>$ tags containing alternative text are provided for all of your site graphics and photos.

$\square$ All copyrighted material is used with permission.

$\square$ Grammar, spelling and punctuation are correct and follow a consistent style.

$\square$ You do not advertise, endorse, link to or include logos for commercial entities.

$\square$ Your site complies with "Rights, Rules, Responsibilities," as well as the Equal Opportunity Policy.

$\square$ Your site represents University well.

Highly recommended features ( $\checkmark$ the available feature) 


\section{Bringing Consistency in the Websites of Higher Educational Institutes (HEIs) of Pakistan}

$\square$ Your site title is placed prominently on every page.

$\square$ Your site has a logical naming convention for Web addresses, menu labels and page headers.

$\square$ Your navigation uses straightforward wording, in one- to three-word phrases.

$\square$ Your navigation is grouped in clusters of six or fewer items.

$\square$ Every page in your site can be accessed from some level of your navigation.

$\square$ Interactive elements in your site behave consistently; so that users can predict what will happen when they click on an item.

$\square$ When making hotlinks use descriptive two- or- three-word phrases.

$\square$ All links to pages within your own site open up in the same window.

$\square$ Your site uses a consistent practice for opening up new windows for links that take the user outside of your site.

$\square$ Proper names are used correctly.

\section{Part II}

\section{Comparison of five websites}

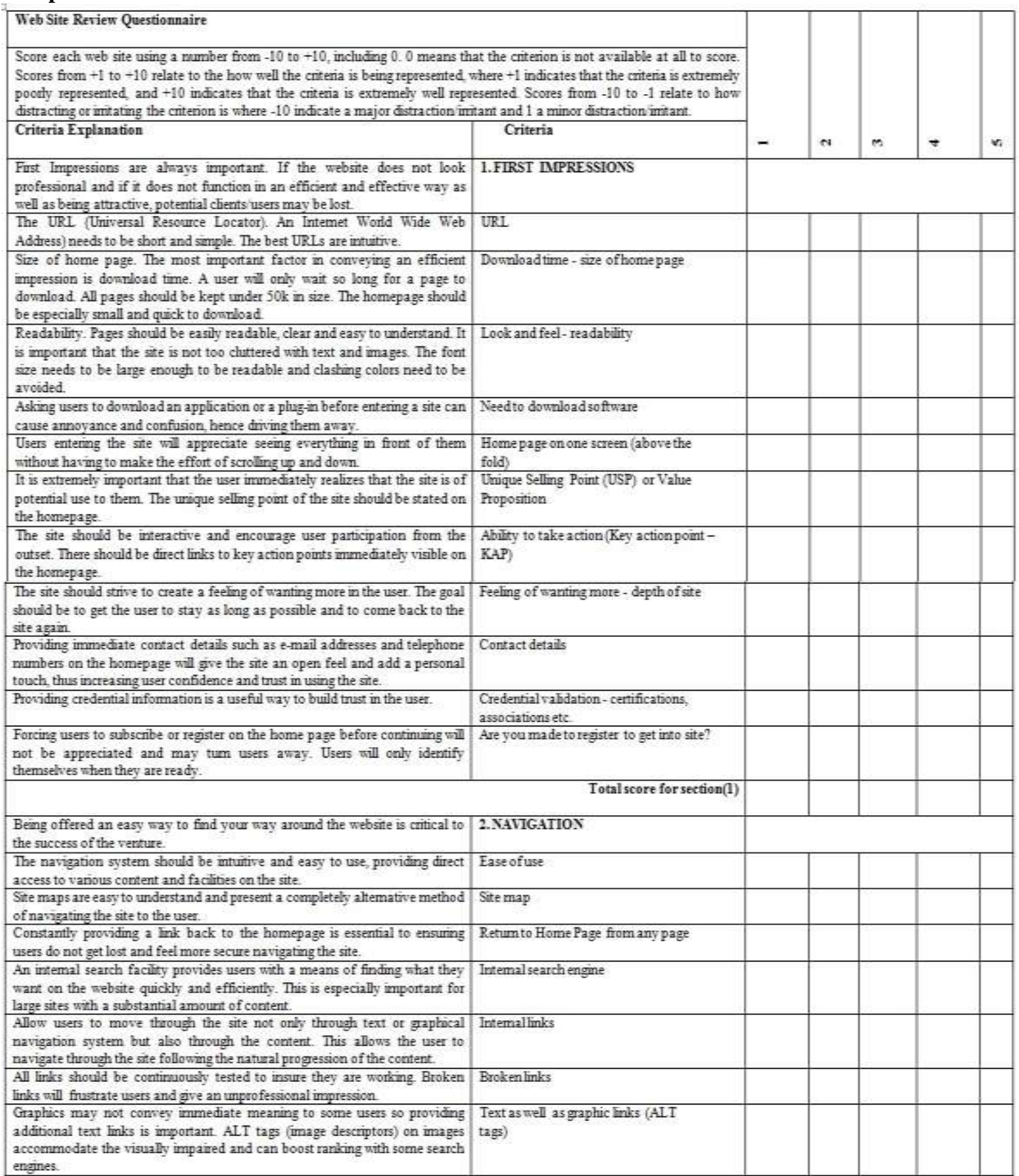


Bringing Consistency in the Websites of Higher Educational Institutes (HEIs) of Pakistan

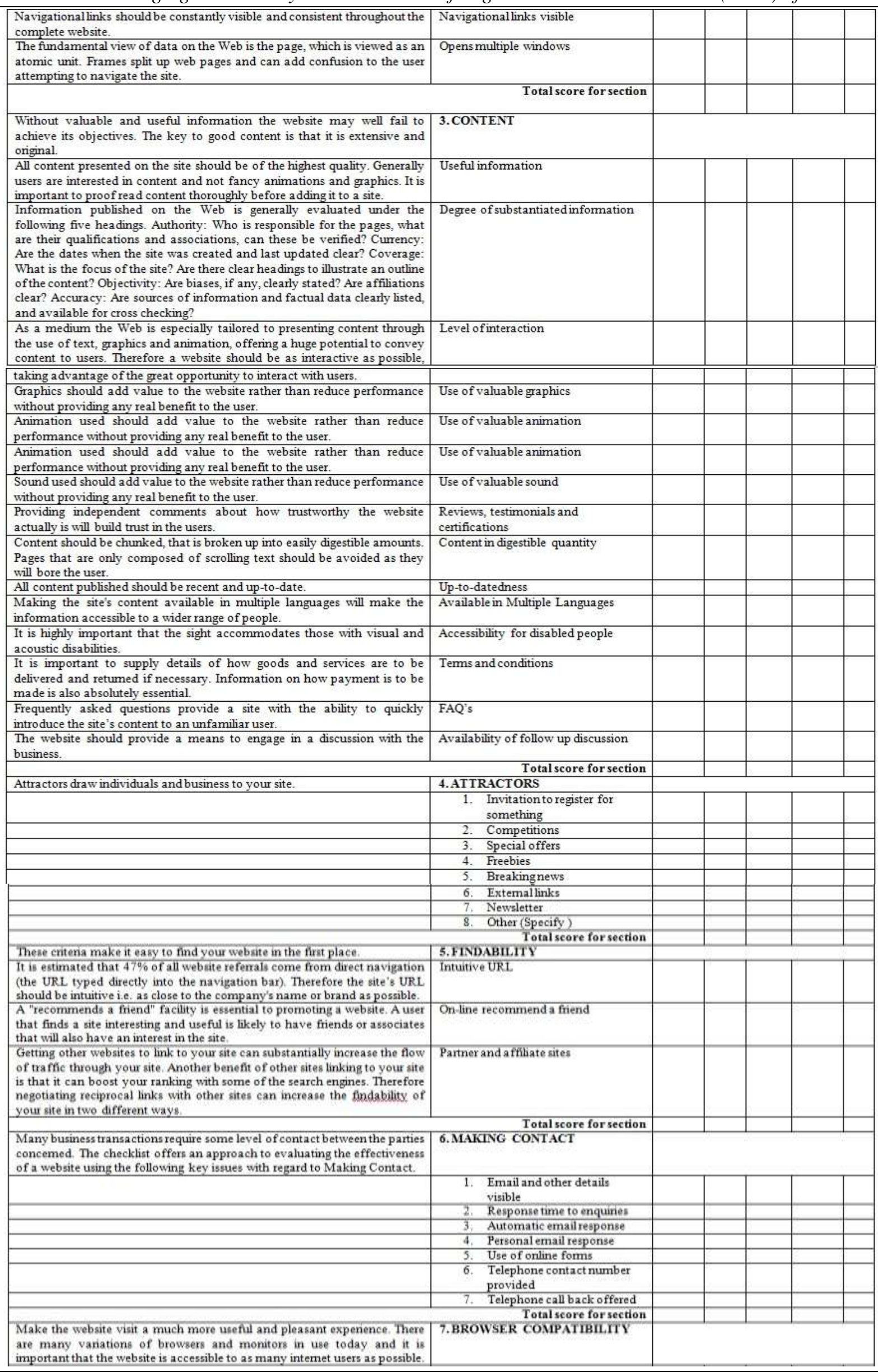


Bringing Consistency in the Websites of Higher Educational Institutes (HEIs) of Pakistan

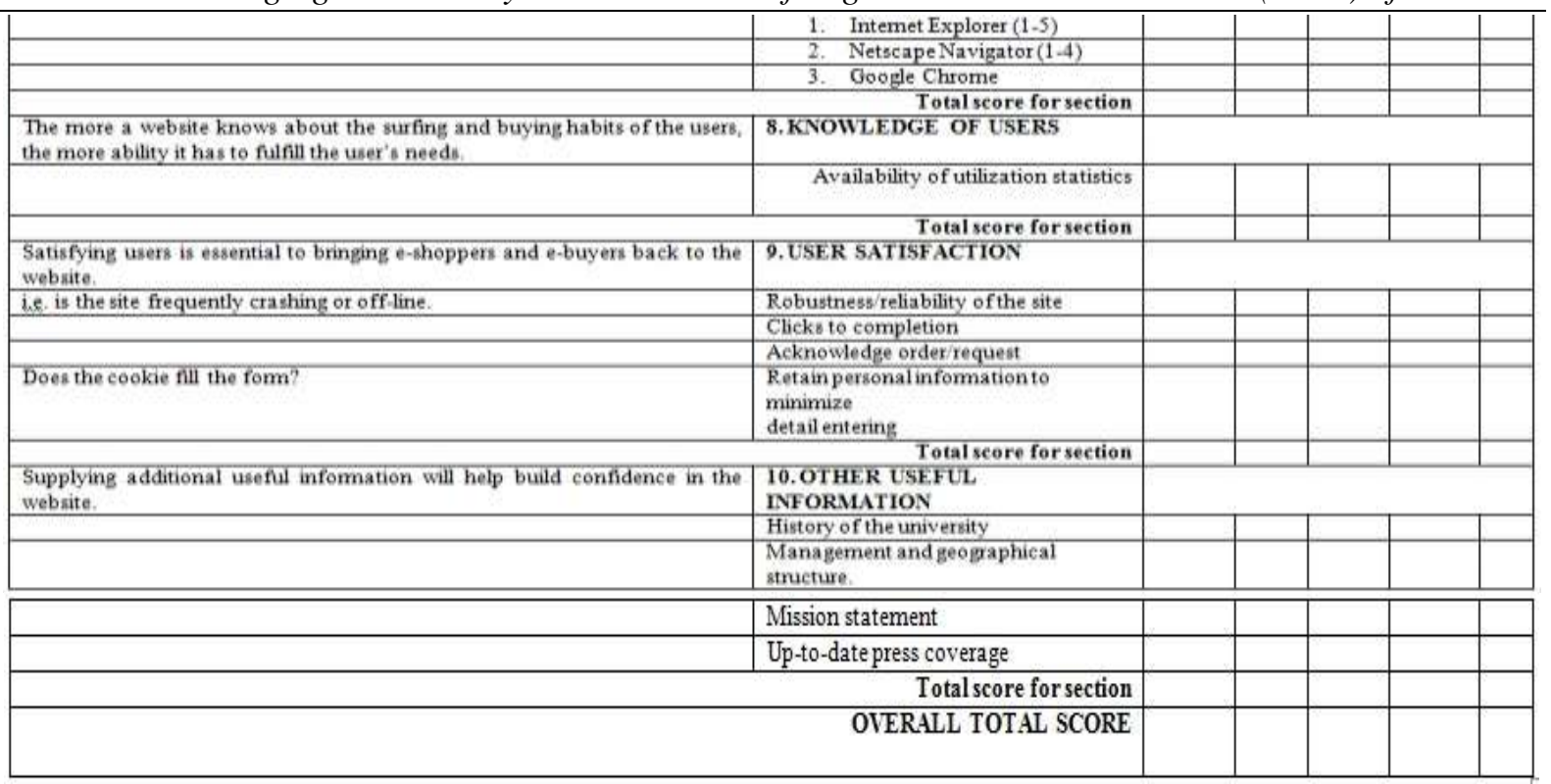

Thank you for completing this questionnaire.

Source of Support: Nil, Conflict of interest: None 